\title{
A study on children who were subjected to physical chastisement in Matale District, Sri Lanka refereed for medico-legal examination.
}

\author{
WMAS Jayasena $^{1} *$, MDS Perera ${ }^{2}$ \\ ${ }^{1}$ Office of the Judicial Medical Officer, District General Hospital, Matale \\ ${ }^{2}$ Department of Radiology, District General Hospital, Matale
}

*Corresponding author: Tel: 0773438354. E-mail address: ajithjayasena@yahoo.co.uk

\begin{abstract}
Introduction: Causing physical injuries to the children by elders has become a common incidence in the society. Surprisingly significant number of school-children is subjected to various types of corporal punishment in the schools, in spite of strict circulars have been implemented by the Ministry of Education to alleviate corporal punishment.

Objectives: To determine the circumstances, nature, causation and category of injuries in children.

Design, setting and method: A retrospective study of 18 out of the 64 children referred to the Medicolegal Unit, District General Hospital, Matale for medico-legal examination from May 2010 to November 2010 were analyzed. All 18 children gave a history of assault and the excluded sample included the children with a history of sexual abuse and those transferred outside the Matale District.

Results: 10 subjects (55\%) showed blunt force injuries such as contusions, abrasions and fractures. One subject showed a ruptured ear drum and another showed a burn injury. 6 subjects (33\%) showed no recent or remote injuries consistent with an assault. Male to female ratio was 1:1 and the most vulnerable age group was $14-17$ years $(50 \%)$. Corporal punishment by teachers were observed in six subjects (33\%) and out of them 02 subjects showed grievous injuries.

Conclusion: Corporal punishment was the commonest presentation in children subjected to physical chastisement in this study sample. This need to be evaluated further and urgent preventive measures should be addressed.
\end{abstract}

Key words: children, physical injuries, corporal punishment

\section{Introduction}

Causing physical injuries to the children by adults has become a common incidence in the society. Studies from many countries in all regions of the world suggest that up to $80-98 \%$ of children suffer physical punishment in their homes, with one-third or more experiencing severe physical punishments [1]. Other than the assaults reported in homes, significant number of school-children is subjected to various types of corporal punishment in schools, in spite of strict circulars have been implemented by the
Ministry of Education to alleviate corporal punishment.

\section{Objectives}

To determine the circumstances, nature, causation and category of injuries in children.

\section{Method}

A retrospective descriptive study based on the data of 18 children with a history of assault referred to the Medico-legal Unit, District General Hospital, Matale for medico-legal 
examination from May 2010 to November 2010 were analyzed.

All the children were examined with Medicolegal Examination Forms issued by the police and informed written consent was taken from the non alleged parents/relation before commencing medico-legal procedure. A detailed history regarding the date and time of assault/assaults, previous assaults, place of assault, causative weapons, the assailant/assailants involved with the assault and the reason for such assault were inquired from the children. Except few younger children who were unable to give exact date and time of assaults or repeated nature of assaults, all others have given a satisfactory history on the scenarios. A Tamil speaking female nursing officer's support was obtained to get the information from children who can't speak Sinhala. It was difficult to get the history from one child due to acute stress reaction following the assault and the child was able to give the history after the follow up at the psychiatric unit. Skeletal survey was performed in three children and six children were referred to the Consultant Psychiatrist to get his opinion. All the injuries examined were photographed with a scale.

\section{Results}

Out of 18 children examined, 10 showed blunt force injuries such as contusions, abrasions and a healed fracture (one subject). 03 had injuries at different stages of healing. One showed a healed green stick fracture with periostial reaction in the second metarcarpal bone in left hand. One child had a ruptured ear drum and another showed a recent superficial burn injury with blister formation on the palm. 06 children showed no recent or remote injuries consistent with an assault.

Distribution of soft tissue injuries were as follows; upper limbs and lower limbs - 04 subjects, front chest, back, upper and lower limbs - 03 subjects, head - 01 subject, head and upper and lower limbs - 01 subject.
Male to female ratio was $1: 1$ and the most vulnerable age group was $14-17$ years. When considering the assailants, corporal punishment by teachers was observed in six children and one was a student monk. 02 out of six children subjected to corporal punishments by teachers had grievous injuries. One child was assaulted by two teachers (kicking and beating with hands) in one incident. Two students were spanked. Injuries observed were tramline contusions(three cases), haematoma in upper limb (one case) crescentic abrasions on ear lobes (one case) due to dragging the child by ear and rupture of ear drum (one case) by slapping.

Out of 18 children 03 had grievous injuries. Fatal injuries among children due to assault were not reported throughout the period of this study.

Ten children were assaulted by family members such as stepfather/step mother, elder brother/sister or relatives living with the family of the children. Two were assaulted by their neighbours. The main reason for the assault is that the behavior of the children was not tolerated by the assailants.

Considering the causative weapon, 06 were beaten with canes, wooden sticks and 04 were beaten with hands and one sustained injury by throwing a stone at him. One had a superficial burn with blister formation by placing a burning slice of camphor on the palm.

\section{Discussion}

Making the diagnosis of physical abuse requires a high index of suspicion because the presentation of abuse is quite variable[2]. In clinical situations, a child may present with a main complaint of an injury, a chronic somatic or behavioral problem, or seizures or unresponsiveness, or the findings of physical abuse can be discovered incidentally[2]. In our study all the children revealed some form of assault by known adults and all were presented with injuries. Six subjects had no injury. When a 
child presents with an injury or without injury, the most important elements of the history to assess are whether the explanation given is plausible as a means of causing injury, and whether the developmental level of the child is consistent with the history[3]. This is particularly important when a child is presented with a history of assault but in the absence of injury, there may be fabricated stories or false allegations against the alleged party. However, in this study there was no problem with the subjects presented with injuries, and the subsequent police investigations have revealed the assailants have admitted that they have beaten the children.

There were two types of circumstances observed in this study. One was physical punishment/assault occurred at homes and the other type was the corporal punishment in schools. Incidence of corporal punishment among school children shows a significant increase in this sample. Punishment is defined as the application of a negative stimulus to reduce or eliminate a behavior[4]. There are types typically used with children: punishment involving verbal reprimands and disapproval and punishment involving physical pain, as in corporal punishment[4]. In this sample three students were hit by canes and wooden poles; one student was hit by open hand upon the ear and another student was assaulted by kicking while hitting him with bare hands.

Another case revealed a teacher has twisted the upper arm of a student which had a sprain following an accident recently. A student monk in this sample showed multiple contusions of varying stages of healing who was beaten by the chief priest of the temple where he was accommodated.

Except two students who were spanked showed no injuries on the skin all other students showed tramline contusions(three cases), haematoma in upper limb (one case) crescentic abrasions on ear lobes (one case) due to dragging the child by ear and rupture of ear drum (one case) by slapping. Fatal injuries among children due to assault were not reported throughout the period of this study and two had injuries of grievous nature. The most vulnerable group in corporal punishment in schools in this study was the 14-17 years. This could be directly related with their behavior, but behavioral pattern of teachers should also be analyzed at the same time to conclude it precisely which was not done in this study.

Because of the negative consequences of corporal punishment in the managing undesired behavior in children, the Ministry of Education had issued a circular in 1927 with certain limitations in its infliction. There, it reminded teachers that there is no surer sign of a teacher's incapability than inability to maintain order and secure attention without the aid of corporal punishment[5][6]. In 2005 whatever corporal punishment was banned by its circular No: 2005/178[7]. Simultaneously it was also banned by the Corporal Punishment (Repeal) Act, No.23 of 2005[8]. Section 308A has been included in the Penal Code which state that it is an offence to willfully assault, illiterate, neglect, abandon or make the child suffer, cause injury to physical and mental health of the child under 18 years of age. The Child Protection Authority Act was established in November 1998 (Act No:50, of 1998) for the purpose of formulating a national policy for the prevention of all forms of child abuse and also for the co-ordination and monitoring of all forms of child abuse in Sri Lanka.

In spite of all these measures it is obvious that the students are subjected to corporal punishment regularly. The simplest explanation of such assaults by teachers is that they punish students to maintain discipline. Furthermore, it appears that corporal punishment in schools is under-recognized because of cultural attitudes and a reluctance to report private matters to the authorities, together with a fear that reporting may make matters worse[1]. There is still a tendency (both in developed and developing countries) to see physical punishment of children as normal[1]. 
Violence against children in the family may frequently take place in the context of discipline and takes the form of physical, cruel or humiliating punishment[9]. The subjects assaulted in the domestic environment in this study too, revealed the same circumstances. In two occasions police have involved in the initial investigations of the assault following the complaints made by the neighbours. One child was referred by the paediatrician who showed injuries on the skin and distressed behavior.

Management of relevant cases to the psychiatric unit while performing medico-legal investigation, together with changing their environment, too, showed a dramatic change of the behavior of the children. This improvement was detected in four children referred to the psychiatric unit.

The skeletal survey of three cases was helpful in finding out a healed fracture with peri-osteal reaction in the second meta carpal bone in a hand in one subject. It was consistent with non accidental injury and there was no suitable explanation for the causation by the parents.

\section{Conclusion}

Corporal punishment was the commonest presentation in children subjected to physical chastisement in this study sample. This need to be evaluated further and urgent preventive measures should be addressed. Furthermore, it is essential to study more on corporal punishment in schools and to study on awareness of circulars and laws among teachers. There is abundant evidence that the persistent and deep seated harm results from physical punishment of children by their parents and teachers[10].

\section{Acknowledgement}

We extend our sincere thanks to Dr.T.F.Kamaldeen for assisting us in preparing this document.

\section{References}

1. Editorial, The epidemic of violence against children, tropej.oxfordjournals.org, p 295.

2. Sirotnak AP, Krugman RD. Physical abuse of children: an update. Paediatric Review. 1994;15:394-399.

3. Wissow L. Child abuse and neglect. N Engl J Med. 1995;332:1425-1431.

4. Committee on Psychosocial Aspects of Child and Family Health. American Academy Of Paediatrics. Paediatrics. 1998;101(04):723-728.

5. Circular No.E 36 Department of Education, Corporal Punishment in Schools. 21.12.1927.

6. Circular No.26 of 1961, Department of Education, Corporal Punishment in Schools. 21.07.1961

7. Circular No.2005/17 Department of Education, Corporal Punishment in Schools. 11.05.2005.

8. Corporal Punishment (Repeal) Act, No.23 of 2005.

9. Pinheiro PS. Report of the independent expert for the United Nations study on violence against children.WHO, New York, November 2006. www.violencestudy.org

10. Waterston T. Giving guidance on discipline. Br Med J 2000;320:261-2.

\section{Author Contribution}

Design to the study - WMASJ

Supervision to the study- WMASJ

Analysis of the data- WMASJ, MDSP

Interpretation of the results- WMASJ, MDSP

Writing the manuscript - WMASJ

Revising the manuscript- WMASJ 